\title{
A Publicização da Noção de Pessoa Jurídica como Fator de Construção da Dogmática do 'Estado de Direito'.
}

\author{
Maren Luimarães Laborda
}

Assessora Jurídica do Município de Porto Alegre - SMF. Professora de História do Direito e de Direito Romano na PUC-RS e UNISINOS. Mestranda em Direito Público na UFRGS.

INTRODUÇÃO

$$
4 \frac{3}{\text { essoa }}
$$

, segundo a teoria tradicional do direito civil, é uma criação do Direito para designar sujeitos de direito, isto é, quem tem aptidão para ser sujeito - potencial ou atual - de relações jurídicas. Enquanto noção técnica, começou a ser utilizada no medievo e só se tornou precisa em correlação com a de 'sujeito de direito', operada pela Pandectística, no âmbito do direito privado. A identificação entre as noções de 'pessoa' e de 'sujeito de direito' em um só conceito, o de personalidade ou capacidade de direito, entendido como capacidade de possuir direitos e obrigações, remonta à filosofia prática de Kant, ${ }^{1}$ e seu centro é o conceito de dever, que se revela pelo discernimento moral (mo qual a necessidade prática expressa na lei moral implica a existência de liberdade) e o de 'relação de dever', que põe, de um lado, o obrigado e, de outro, aquele para quem o dever existe e que é, no caso do dever jurídico, o titular dos direitos subjetivos respectivos. Os representantes da filosofia clássica alemã, ao adotarem a concepção kantiana de pessoa, deram-lhe, contudo, uma nova dignidade, no sentido de conceber os direitos subjetivos como atributos necessários do homem enquanto pessoa - ser dotado de liberdade -, na medida em que eles garantem o seu agir autônomo.

A expressão 'sujeito de direito', por conseguinte, designa o complexo de direitos e deveres, cuja unidade é expressa figurativamente no conceito de' 'pessoa'. 'Pessoa'(natural ou jurídica) é, então, uma unidade personificada de normas jurídicas que impõem deveres e conferem direitos. ${ }^{2} \mathrm{Na}$ maioria dos países que ado

Cf. STRANGAS, Jean. Les implications philosophiques de la notion de sujet de droit. Archives de Philosophie du Droit. Paris: Sirey, 1990, p. 128. Segundo o autor, (pág. 131) a concepção kantiana de sujeito de deveres e obrigaçóes jurídicos parte de sua concepção de personalidade, em que esta, componente da liberdade do 'homem fenomênico'- o obrigado em geral - aparece como uma grandeza invariável. Dado que, em Kant todos os homens são iguais na medida em que são sujeitos da lei moral e dotados de liberdade, todos têm acesso, da mesma forma, aos direitos subjetivos. Daí a identificação da personalidade com a capacidade jurídica (com a capacidade de ter direitos e obrigaçóes), que se manifesta no Código Civil Alemão.

2 Cf. KELSEN, Hans. Teoria Pura do Direito. Coimbra: Arménio Amado Editor, 1979, pp. 236 e ss. 
tam o sistema de direito romano-germânico, ${ }^{3}$ as pessoas jurídicas têm sua natureza descrita conorme imputações de direito privado ou de direito público. No plano do direito público, o Estado - a organização política da sociedade - é concebido como uma pessoa jurídica (sujeito de direito) que atua através de seus órgãos, construção que se operou definitivamente na doutrina germânica, na segunda metade do séc. XIX, em conseqüência da publicização da problemática da personalidade jurídica.

Através da transplantação da noção pandectística de pessoa jurídica, os juspublicistas alemães fizeram do princípio da personalidade do Estado o ponto de partida e a base de toda a construção jurídica do direito público, da mesma forma que a figura do homem - 'sujeito de direito' - estava posta no centro da construção dogmática do direito privado. Partindo de tais premissas, este estudo procura identificar os princi pais traços do caminho percorrido até a definitiva consagração da personalidade jurídica do Estado como fator de construção da teoria jurídica do 'Estado de Direito', o que passa por verificar, ainda que em linhas gerais, os antecedentes teóricos do problema, bem como por clarificar a que necessidades históricas e políticas tal teorização respondeu.

\section{I - EVOLUÇÃO DA NOÇÃO DE 'PES- SOA JURÍDICA}

No Direito Romano antigo, a palavra 'pessoa' tinha o significado normal de 'homem', sem qualquer alusão à sua capacidade. Embora largamente empregado, o termo persona não

inha um valor técnico, e tanto era 'pessoa' o homem livre quanto o escravo - persona servi , ainda que este não fosse considerado sujeito de direito. Para o ser sujeito de direito, além da condição 'ser homem', concorriam mais três, a saber: ser livre, cidadão e senhor de si mesmo sui iuris. Só nos textos pós-clássicos é que emerge um emprego diverso do termo, para exprimir uma noção que se avizinha ao que os modernos entendem por 'capacidade jurídica'. $\mathrm{Na}$ compilação justinianéia, o termo continuou ser utilizado de modo genérico, e os glosadores civilistas bolonheses continuaram a não lhe atrbuir, em referência ao homem, qualquer particular significação jurídica.

Isto não quer dizer que os romanos não conhecessem as realidades abstratas que o termo 'pessoa jurídica', surgido na experiência canonística, veio a designar ou mesmo que, no âmbito de seu ordenamento jurídico, inexistissem soluções para as situações de fato que superam a consideração do homem singular enquanto centro de imputação de relações jurídicas. Orestano ${ }^{6}$ estudando a relação entre situações com tratamento unificado e os fenômenos de imputação na experiência romana, aponta importância e antigüidade da configuração material do problema, compreendendo tanto situações pessoais concebidas em sentido material quanto imputações referidas a entidades materiais em sentido próprio ou a complexos patrimoniais, ou seja, uma concepção que punha as coisas, os bens, no centro das relações de imputação. O autor descreve também o caminho através do qual de uma concepção material, concreta, a jurisprudência romana, ao longo de séculos, chegou a uma concepção

3 Classificação conforme René DAVID iñ: Os Grandes Sistemas de Direito Contemporâneo.São Paulo Martins Fontes, 1993

- Cf. ORESTANO, Riccardo. Il"Problema delle persone giuridiche" in Diritto Romano. Turim: Giappichelli, 1968, p.9.

ORESTANO, (nota 4), pp. 106 e ss.

ORESTANO, (nota 4), p. 106.

Revista da Faculdade de Direito da UFRGS, v. 19, Março/2001 abstrata, de separação e independência do 'todo' em relação a seus elementos constitutivos (m teriais ou pessoais). O exemplo dessa evolução é a noção de hereditas, que assume um valor paradigmático, pois, de um significado inicial concreto e material - res -, passa por uma desmaterialização, no período clássico, para ser considerada res incorporales, até chegar, nos textos justinianeus, como universitas.

De fato, a enunciação do que se pode chamar, em termos modernos, de 'coletividade', se efetuava mediante um substantivo no singular-municipium, colonia, civitas, sodalicium, etc. - ou mediante a indicação, no plural, de seus componentes - municipes, coloni, cives, sodales, etc. A expressão municipia, por exemplo, surgida na época imediatamente anterior ao ano 212 a . c. era utilizada para designar as comunidades incorporadas à cidadania romana que perdiam sua soberania política e se regiam, na esfera patrimonial, pelo direito privado. Da mesma forma, termos como collegia, sodalitates designavam realidades semelhantes - corpos coletivos que se regiam, na esfera patrimonial, pelo direito privado -

No campo da organização pública, o centro de imputação ou referência de relações jurídicas de interesse geral evoluiu do populus romanus, que, na época republicana coexistia com as várias figuras de collegia e associações religiosas e assistenciais com relevância pública, para o princeps e as particulares figuras da organização administrativa imperial, princi palmente o fiscus. O populus romanus, para cuja composição contavam unicamente as relações entre pessoas juridicamente equiparadas - os patresfamilias , não foi sujeito ativo ou passivo

de direitos patrimoniais no sentido do direito privado até o Princi pado, quando iniciou a sua sujeição parcial através da criação do Fiscus patrimônio destinado à administração imperial e que se distinguia do erário público (aerarium populi Romant), o patrimônio verdadeiro e próprio do Estado. Embora o Fisco pudesse submeter-se a regras de direito privado, como qualquer cidadão, importantes privilégios o colocavam acima do direito privado, tanto do ponto de vista do direito material quanto formal. Daí não haver, no âmbito da experiência jurídica romana, a abstração 'pessoa jurídica' referida à organização política ou mesmo às associações regidas pelo direito privado.?

1.1 - Atribuição de valor técnico à expressão 'persona': direitos subjetivos e personalidade jurídica.

Foi na canonística, mais precisamente na obra de Sinibaldo de Fieschi (futuro papa Inocêncio IV), que se passou a aplicar correntemente o termo persona para designar entidades coletivas com uma configuração unitária abstrata distinta de seus membros particulares. Os canonistas foram os primeiros a utilizar expressōes como persona universitatis, persona collegii e a formular a teoria da pessoa jurídica como personae fictae. Os Comentadores (prin ci palmente Bártolo de Sassoferrato e Baldo de Ubaldi) continuaram a sublinhar que a noção tratava de construção intelectual da ciência jurídica e, finalmente, no séc. XVI, mais precisamente no ano de 1601 , surgiu a primeira monografia (de Nicolaus Losaeus), editada em Veneza sob o título Tratactus de iure universitatis, com o argumento de que as

Para essas considerações, ver também: IGLESIAS Juan. Derecho Romano. Historia e Instituciones. Barce lona: Ariel, 1993, pp. 107/108 e 144 a 147; CATALANO, Pierangelo. Diritto e Persone. Studi Su Origine Lna: Ariel, 1993 pp. $107 / 108$ e E Attualità Del Sistema Romano. Turim: Giappichelli, 1990, Capítulo V, pp. 163/188; COUTO E SL VA, Almiro. Os indivíduos e o Estado na realização das tarefas públicas. Informação por correio eletrônico. http:) /orionufrgs.br/mestredir, p. 4.

Revista da Faculdade de Direito da UFRGS, v. 19, Março/2001 
universitates são um fingimento, um corpo abstrato, cujo significado é inventado pelo intelecto. ${ }^{8}$

O problema da 'pessoa jurídica' permeou toda a civilística, do séc. XVI ao séc. XVII, que o tratou segundo uma concepção naturalística e objetiva. Duarenus (1509-1559) aplica o termo persona tanto às universitates quanto a seus componentes, anteci pando, em muitos anos, um conceito unitário de 'personalidade jurídica'. Domat (1625-1696) dedica, nas Loix civiles, um único título às personnes (comunidades eclesiásticas e laicas), definidas como assembléias de muitas pessoas unidas em um 'corpo' formado com a permissão do príncipe, para um bem público permanente, distintas das pessoas particulares. ${ }^{9}$ Mas foi só no final do séc. XVI que apareceram as primeiras tentativas de clarificar a relação entre o elemento naturalístico - o homem enquanto entidade física real - e a sua consideração do ponto de vista do Direito - o homem enquanto entidade juridicamente relevante -, reservando-se para este último a qualificação, cada vez mais específica e técnica, de persona. Puffendorf (1632-1694) elabora, finalmente, o conceito unitário de persona moralis, destinado a reunir, sob uma única noção geral, as personae simplices e as personae compositae.

A passagem para uma concepção eminentemente subjetivistica iniciou no curso do séc. XVIII, quando, retomando a temática principal do individualismo jusnaturalista, que fez coincidir o status hominis naturalis e o status

hominis civilis - a noção de homem como um dado naturalístico e a noção de pessoa como um dado jurídico-, juristas e filósofos sustentaram que todo homem é, por si mesmo, portador de 'direitos subjetivos', que se podem reportar ao seu 'poder da vontade', elevado a sinal natural de sua personalidade e a elemento motor das relações jurídicas que estabelece. ${ }^{11}$

Com efeito, desde Grotius (1583 1645), já se vinha tratando da idéia de direito subjetivo como faculdade de querer ou fazer qualquer coisa, ${ }^{12}$ enumerando-se, até, os vários tipos de 'direitos' que esse poder implica, tai como: poder sobre si mesmo (potestas in se) liberdade; poder sobre outros (potestas in alios, como o pátrio poder) e poder sobre coisa (potestas in res, como o domínio/propriedade) Embora não se possa afirmar com precisão o momento em que o termo ius passou a significar direito subjetivo, é certo que é uma noção que marca o nascimento de um tipo de pensamento jurídico de cunho nitidamente individualista, cuja causa longíqua e profunda foi o cristianismo, que revelando o valor do indivíduo, desenvolveu, na Idade Média, novas categorias jurídicas estabelecidas em função do interesse individual e não mais em função da situação social, como a das 'pessoas miseráveis' (miserabiles personae). ${ }^{13}$

Ainda que se utilizasse, no medievo, palavra ius, ela não se aplicava à faculdade de querer ou de agir nem denotava a idéia mesma de faculdade: o ius que cada um reivindicava nada mais era que seu estatuto. ${ }^{14}$ As primeiras

Cf. ORESTANO, (nota 4), p. 12

Cf. ORESTANO, (nota 4), p. 13

Cf. ORESTANO, (nota 4) P.

II Cf ORESTANO (nota 4) $P$. 16 .

${ }^{12}$ Cf. VILLEY, Michel. Leçons d'Histoire de la Philosophie du Droit.(Les origines de la notion de droit subjectif). Paris: Dalloz, 1957, p. 250.

13 Cf. VILLEY, (nota 12), p. 269.

is Cf. VILLEY, (nota 12), p. 271.

Revista da Faculdade de Direito da UFRGS, v. 19, Março/2001 definições claras da noção de 'direito subjetivo' emanaram do grupo de autores da escolástica tardia (Duns Scott e Guilherme d'Occam), lentamente foram transmitidas a juristas - Grotius e seus comentadores (Pufendorf, Feltmann e Thomasius) até receberem uma completa formulação por filósofos como Hobbes ${ }^{15}$ e Gassendi ${ }^{16}$ na esteira de um combate da filosofia moderna contra o direito natural concebido por Aristóteles.

Scott, relevando o papel da razão para conhecer as verdades mais sublimes, acentuou o indivíduo, o singular, frente ao universal, antecipando a modernidade. Para ele, o fundamento do princípio da individuação e a explicação de por que é conhecido o indivíduo não devem ser buscadas em um princípio geral ou em algo extrínseco ao indivíduo, senão nele mesmo (objeto individual e singular).

De outra parte, a crítica de Occam reduziu a nada o antigo direito natural imutável, tendo ele insistido sobre a origem humana e, portanto, arbitrária, convencional, do dominium e da soberania, a origem arbitrária do direito (obra das vontades humana e divina) e a origem arbitrária das sociedades. ${ }^{17}$ Em Occam, pois, acentuação dos limites da razão adquire cará ter extremo, até resultar em uma efetiva cisão entre a filosofia e a teologia. O reconhecimento da primazia do indivíduo leva, em Occam, a um conceitualismo que exclui a existência de outros universais fora de seu conceito e, mais explícito ainda, é o voluntarismo com referên cia a Deus e a acentuação da oni potência divina, até o ponto em que esta se converte na tese básica e chave de toda a sua doutrina filosófica.

Assim, ao antigo direito natural objetivo - uma ordem fixa e imutável estabelecida pela razão universal, em que cada instituição social tem uma estrutura fixa - foi contraposto um direito natural novo cujo conteúdo é negativo: a ausência de vínculos e de regras sociais, de deveres e de comandos, é dizer, o direito de liberdade do indivíduo, cuja origem é puramente humana, convencional. A natureza fez os homens indivíduos, separados e livres, e tais liberdades são dados jurídicos primários que a lei a e convenção modelam em 'direitos subjetivos'. Por conseguinte, a noção primordial do direito é aquele que é dado por natureza aos homens, que as leis civis limitam: é a liberdade, o poder individual.

Essa teorização dos direitos subjetivos respondeu, segundo Weber ${ }^{18}$ às necessidades de uma economia de mercado em expansão, pois, do ponto de vista sociológico e do desenvolvimento da ordem econômica, são particularmente importantes as expectativas de que não se estorve uma ação ou omissão, chamadas de 'faculdades'. Na medida em que tais faculdades importam em dois ti pos de direitos - os de liberdade, que são o simples asseguramento, dentro do

15 Em Hobbes, o único direito que pode subsistir no estado selvagem de naturèza é o de preservação. Além disso, para ele, o direito não significa outra coisa senão a liberdade que cada um tem de usar suas faculdades disso, para ele, o direito não signif́c
naturais conforme à 'reta razão'.

${ }^{16}$ Cf. VILLEY, (nota 12), p. 279, Gassendi, naEthicae (1658), composta contra a ética aristotélica, o ius que o homem possui por natureza comporta a faculdade de sentir, de se mover, etc, enquanto é animal; enquanto ser especial - homem - esse direito comporta a faculdade do raciocínio, de se exprimir, de celebrar contratos, sem que se leve em linha de conta os deveres, os limites que a natureza impóe à liberdade.

17 Cf.PANLÁGUA, Jose Maria Rodriguez. Historia del Pensamiento Juridico. Vol. I. Madrid: Universidad Complutense, 1988, pp. 89 a 104.

18 WEBER, Max. Economia y Sociedad. Esbozo de sociología comprensiva. México: Fondo de Cultura Económica, 1992, p. 532/533.

Revista da Faculdade de Direito da UFRGS, v. 19, Março/2001 
âmbito da conduta juridicamente permitida, contra violações provenientes de terceiros e especialmente da ordem estatal (liberdade de consciência, de trânsito, de disposição, etc.) e os que concedem aos indivíduos a faculdade de regular autonomamente, dentro de certos limites e por meio de negócios jurídicos, suas relações recíprocas - a liberdade de contratação depende da extensão que o ordenamento jurídico conceda ao arbítrio dos indivíduos. Como liberdade, em sentido jurídico, significa ter direitos subjetivos atuais e potenciais, em uma comunidade sem mercado esses direitos não derivam, de modo principal, dos negócios jurídi$\cos$, senão de preceitos imperativos e proibitivos do direito objetivo. A troca é, sob o domínio de um sistema de direitos subjetivos, um negócio jurídico: aquisição, cessão, renúncia de pretensões jurídicas. Destarte, a soma dos direitos legitimamente adquiridos e das obrigações legais de um indivíduo - a sua situação econômica legítima - determinam-se, "em parte por aquisições hereditárias derivadas de relações de direito familiar e em parte também - direta ou indiretamente - através dos negócios jurídicos"19 que celebra.

Quando da elaboração sistemática da doutrina geral do direito privado pela Pandectística alemã entre o fim do séc. XVIII e início do séc. XIX, em que aquele foi, segundo o espírito e a doutrina da época, concebido e articulado em torno da noção de 'direito subjetivo', isto é, como um 'sistema de direitos subjetivos', consolidou-se a concepção subjetivística da personalidade jurídica. Tal concepção subjetiva da personalidade ao identificar a persona sujeito de direito - com o seu substrato material (o homem), comportou duas orientações de pensamento diametralmente opostas e, todavia,

WEBER, (nota 18), p. 534

Cf. ORESTANO, (nota 4), pp. 19/20.

2l Cf. ORESTANO, (nota 4), p. 21 ligadas à mesma matriz subjetivística, a saber: a teoria da ficção e a teoria da realidade. A primeira afirma que só o homem, enquanto ser que possui uma vontade, pode ser sujeito de direito com existência real, sendo artificiais todos os demais sujeitos; a segunda procura de monstrar que todos os 'sujeitos de direito' são igualmente dotados de uma existência e vontade 'reais'. ${ }^{20}$

1.2 - A tese da 'pessoa jurídica' e as teorias sobre a sua natureza jurídica

No processo de construção sistemática de uma noção geral de 'sujeito de direito', apareceu em 1807, pela primeira vez, a voz 'pessoa jurídica' (juristiche Personen), na obra do juris ta alemão Arnold Heise, compreendendo, sob um único conceito, contraposto às pessoas físcas, tudo o que não fosse o homem singular (Alles auBer den einzelnen Menschen) e que pudesse ser reconhecido em um Estado como 'sujeito de direito' cujo substrato é constituído do homem singular (quando exerce determinada função, como nos serviços públicos), de agrupamentos humanos (universitates), de um conjunto de bens destinados a fins de interesse geral ou quaisquer outros elementos. ${ }^{21}$

Reelaborando a tese de Heise, Savigny afirmou a natureza fictícia da personalidade jurídica, ao entender que, em todo direito subjetivo, existe a causa da liberdade moral ínsita ao homem e, por essa razão, o conceito de pessoa como 'portadora' (Träger) ou 'sujeito de direito' (Rechtssubject) deve coincidir com o conceito de homem, uma vez que só este é capaz de direitos. Daí a pessoa jurídica, sujeito artificil, criada por 'simples ficção' se distingue das corporações e das fundações cujo substrato é uma associação de pessoas ou um complexo de bens, respectivamente. ${ }^{22}$ À diferença dos canonistas e civilistas medievais, Savigny considera tal ficção não uma criação intelectual da ciência jurídica, mas um "instrumento técnico de que dispõe o legislador", que 'finge', ante uma associação de homens ou de bens, a existência de uma unidade, considerada como 'pessoa' e, como tal, 'sujeito de direito'. ${ }^{23}$ Puchta, por sua vez, aderindo à tese da ficção, considera haver personalidade jurídica só quando há uma disposição legislativa que reconhece a condição de 'sujeito de direito' de alguém ou de algo. Por isso, reagrupa as várias figuras de pessoas jurídicas sob o único conceito de universitates, distinguindo por universitates personarum as corporaçōes e por univesitates rerum as fundações. ${ }^{24}$

O conceito de personalidade jurídica, via de conseqüência, correspondeu à solução do problema relativo à posição das associações e da legitimação de seus órgãos no tráfego negocial e nos procedimentos judiciais, pois ele implica a total separação das esferas jurídicas dos membros da esfera jurídica independente da própria associação, de modo que só certas pessoas, juridicamente autorizadas, podem obrigar a associação. Essas relações jurídicas, porém, não afetam as pessoas nem os patrimônios dos associados nem valem como contratos destes. Por igual, as exigências e prestações dos associados, enquanto tais, vinculam, segundo o estatuto, os direitos e obrigações de seus patri-

Cf. ORESTANO, (nota 4), p. 22

23 Cf. ORESTANO, (nota 4), p. 24

24 Cf. ORESTANO, (nota 4), p. 22

25 WEBER, (nota 18), pp. 566/567. Neste passo, o autor considera que, a rigor, no âmbito do direito, o conceito de pessoa é sempre juŕdico e, por isso mesmo, a noção de personalidade jurídica é sempre tão artíficial quanto a questão acerca do que sejam "as coisas" em sentido jurídico.

* Cf. ORESTANO, (nota 4), p.26.

C. ORESTANO, (nota 4), p. 30. mônios privados e não o patrimônio social. Po esta via, o conceito de personalidade jurídica se estende para abarcar a disposição de bens econômicos cuja utilização se atribui a uma pluralidade de pessoas determinadas sem que, com isso, se forme uma associação. Este é, precisamente, o caso das fundações - patrimônio afetado a um fim - cujos interesses são representados autonomamente no comércio jurídico por um titular a quem, de acordo com determinadas normas, reconhece-se tal caráter. Enfim como diz Weber, "de um ponto de vista técnico-jurídico, o conceito de personalidade jurídca é totalmente supérfluo quando não se atribui a uma associação nenhum patrimônio em nome do qual seja possível celebrar contratos." ${ }^{25}$

Contra a tese da ficção e a ela contemporânea, surgiu a teoria da realidade, ou orgânica, pugnada por Georg Von Beseler e Otto von Gierke, que aprofundaram o problema do ponto de vista da tradição germânica e das suas formas associativas de tipo comunitário (Genossenschaften), tratando de resolvê-lo em uma concepção que considerava a pessoa jurídica como um 'organismo natural' ${ }^{26}$ Além da teoria orgânica, outras perspectivas sobre a natureza da pessoa jurídica também surgiram no curso do séc. XIX e começo do séc. XX, tais como a desenvolvida por Aloys Brinz (do patrimônio destinado a um fim - Zwecksvermögen), por Zitelmann (teoria da vontade Willenstheorie) e por Ennecerus (teoria da organização - Einrichtungstheorie). ${ }^{27}$ Foi a concepção orgânica, entretanto, que acabou por 
se tornar o centro da teoria do Estado como pessoa jurídica.

II - A CONSTRUÇÃO DA PESSOA JURÍDICA PÚBLICA ATRAVÉS DA TEORIA ORGÂNICA

O tratamento unificado de situações reconduzíveis à imputação de interesses gerais iniciou no período medieval, com os esquemas de collegia, corpora e universitates, bastando pensar na teoria das communia civitatis e do direito estatutário, na relevência do direito público nas corporações medievais e na doutrina canonística dos collegia necessaria et naturalia. No entanto, a primeira teorização das pessoas públicas distintas das pessoas privadas apareceu no fim do séc. XVI, na obra de Gregório Tholosanus - Syntagma - ${ }^{28}$ e a partir de Grócio e Hobbes, começou-se a falar do Estado como corpus morale, persona civilis, persona artificialis ou de um corpus fictitium. Pufendorf, seguido por Thomasius, distinguia tanto as personas simplices como as personae compositae em públicas e privadas, e o francês Jean Domat identificava todo tipo de communauté a parte do corps de l' État.

Inicialmente, na doutrina oitocentista do sujeito de direito e seus direitos subjetivos, o problema da pessoa jurídica foi visto sob o prisma do direito privado, em parte pela escassa elaboração doutrinária cujo objeto fosse o direito público e, em parte, pelos motivos ideoló-

Cf. ORESTANO, (nota 4), p. 32

2 Cf. ORESTANO (nota 4), pp. 33/34.

3 Cf. ROTTLEUTHNER, Hubert. Les métaphores biologiques dans la pensée juridique Archives de Philosophie du Droit. Paris: Sirey, 19, p. 216.

${ }^{31}$ CF. ROTTLEUTHNER, (nota 30), p. 216, uma metáfora é uma transferência, particularmente de conceitos. Na historia da ciência, a biologia, depois de Darwin, tornou-se a disciplina paradigma, ou dirigente, e seus conceitos, modelos e perspectivas tais como 'desenvolvimento', 'Iuta', 'vida' 'e 'organismo', foram transfericonceitos, modelos e perspect
dos para outras disciplinas.

Revista da Faculdade de Direito da UFRGS, v. 19, Marco/2001 gicos que fizeram a Escola Histórica reagir contra a idéia jusnaturalista e revolucionária de que o Estado pudesse ser um ente cuja personalida de não coincidisse com a do soberano, a ponto de Savigny sustentar que só as relações de direito privado pudessem referir-se à artificial capacidade da pessoa jurídica, na medida em esta qualificação - pessoa jurídica - põe em relevo unicamente a capacidade patrimonial, traduzindose por um sujeito capaz de ter um patrimônio.

2.1 - O Estado como uma estrutura orgânica

Conquanto as comparações entre o $\mathrm{E}$ tado, a sociedade, a Igreja ou outras coletividades e os indivíduos - seus corpos, atributos físicos e psíquicos - seja "tão velha quanto o mundo", ${ }^{30}$ os termos 'orgânico/inorgânico' como hoje são entendidos só foram estabelecidos no fim do séc. XVIII, e Otto Gierke foi o primeiro a utilizar a metáfora do 'organismo'de um modo absolutamente rigoroso. ${ }^{31}$ Esta concepção não foi, contudo, absolutamente nova, pois Albert van Krieken, em 1873 já havia reconhecido Estado como pessoa jurídica, na esteira dos ensinamentos de Gerber, que postulara a personalidade jurídica do Estado cujos direitos eman vam de seu 'poder de querer', isto é, 'poder de dominar' que se chama 'poder público', atuante através de seus órgãos. Pode-se dizer, então, (Estado-pessoa moral, Estado-poder público e o conceito de órgão) que influenciaram toda a geração que elaboraria definitivamente a teoria do Estado como pessoa jurídica. ${ }^{32}$

Gierke, um ano depois do aparecimento da obra de Krieken, rejeitou, inicialmente, conceito científico de organismo para concebêlo como "uma concepção geral do ser natural". Para ele, organismo é um conceito transdisci plinar, ligado a um domínio particular da realidade: o do "ser natural vivente" 33 mas não é, apesar disso, somente um produto natural, pois as formações sociais também são organismos no sentido espiritual. Refletindo sobre a natureza do Estado, Gierke acaba por ver nele uma unidade composta cuja vida específica não corresponde à vida de qualquer de suas partes. Daí a pessoa individual em suas relações com o Estado dever ser pensada nâo como um todo completo em si, mas como parte de um todo. ${ }^{34}$

Com a especificação de problemas jurídicos práticos, o conceito de organismo ganhou contornos mais definidos, para apreender a essência, na realidade, das comunidades humanas, das associações (o Estado, a Igreja, a corporação, etc). Assim, visando a construção da 'pessoa jurídica' e do Estado enquanto 'pessoa jurídica', Gierke se opôs à teoria da ficção, para estabelecer a realidade específica das associações enquanto 'organismos sociais'. O Estado, enfim, para Gierke, "é a mais alta e compreensiva forma de Comunidade, não perceptíve para os sentidos, porém real para o espírito, que nos revela uma existência comum humana so- bre a existência individual. Este elemento comum é a unidade permanente, viva, da unidade que quer e obra e na qual se encerra todo um povo". ${ }^{35}$

Sustenta Rottleuthner ${ }^{36}$ que a concepção de organismo, consistente na consideração da pessoa jurídica em sua estrutura interna e de sua relação com outros sujeitos de direito, teve como conseqüências práticas específicas a construção sistemática da ordem jurídica e dos conceitos jurídicos individuais bem como a decisão sobre questões individuais tais como a constituição, a partici pação e a fundação enquanto ato coletivo e não como um contrato, a incorporação/desincorporação, organização e órgão (representação), competências, procedimentos, capacidade legal e responsabilidade da pessoa jurídica. A introdução da metáfora de organismo, ao permitir descrever problemas ou fenômenos jurídicos específicos (estrutura interna das pessoas jurídicas e relações de trabalho coletivo), não foi, contudo, suficiente para a solução construtiva desses problemas como, por exemplo, o da extensão da responsabilidade de uma pessoa jurídica.

Até a difusão da noção de órgão como um conceito da teoria geral do direito, isto é, como elemento estrutural da pessoa jurídica, a meditação da juspublicística - focalizada no Estado - , dava-se em torno da 'subjetividade do serviço', através da distinção, presente na doutrina germânica (Laband e Mohl), entre serviço $(A m l)$ e ti-

32 Cf. LOS RIOS, Femando. Prólogo à obra de JELLINECK, Georg̣ Teoria General de Estado. Buenos Aires: Editorial Albatros, 1970, p. 120. Tradução da segunda edição do original alemãoAllgemeine Staatslehere, pág. $X X X I$.

33 ROTTLEUTHNER, (nota 30), p. 223.

34 ROTTLEUTHNER, (nota 30), p. 224.

${ }^{35}$ GIERKE, Otto van. Die Grundbegriffe des Stasstsrechts un die neuesten Staatsrechtstheorien (1874), apud LOS RIOS (nota 32), p. XIX.

3 ROTTLEUTHNER, (nota 30), p. 227. 
tular do serviço (Amsträger), ${ }^{37}$ e os modelos sobre as quais aquela trabalhava eram o inglês, que concebia o Estado como um agregado, ordenado em função de 'pessoas jurídicas' como a Coroa, o Tesouro, o Almirantado, etc., e o continental, segundo o qual o Estado era composto do príncipe com seus serviços e da pessoa jurídica privilegiada que constituía o Fisco.

\section{2 - A pessoa pública no Polizeistaat}

$\mathrm{Na}$ Alemanha do Primeiro Império (romano-germânico), as relações jurídicas entre o poder público e os súditos repousavam sobre os direitos de superioridade dos príncipes, cuja base era a superioridade territorial (Landeshoheit), e implicavam iura majestatis (direitos de majestade), mais tardiamente, em ius politiae (direito de polícia) e ius sequelae (direito de impor contribuições). ${ }^{38}$ Após a paz de Vestfália, que reconheceu aos estamentos um poder estatal em seus territórios, havia um juiz superior ao qual o poder territorial estava submetido: o Tribunal Cameral do Império - precursor do controle de constitucionalidade material, ${ }^{39}$ de modo que "os súditos podiam valerse dos tribunais imperiais contra o abuso de direitos dos senhores territoriais" ${ }^{40}$ Os limites às prerrogativas dos príncipes, assim, eram os iura quesitae, isto é, direitos adquiridos que, se usurpados, permitiam o recurso aos tribunais imperiais, de vez que, com tal usurpação, ocomera "mudança da ma-

téria de governo em matéria de justiça".

Já na época do Segundo Império, o re gime era caracterizado pela preponderância da polícia (Polizeistaat). De acordo com isto, o Estado era uma 'pessoa ideal', cujos representantes eram o príncipe em pessoa e os funcionários de todos os tipos, de modo que, tendo como tarefa a perseguição dos fins do Estado, tinham à disposição todos os meios para realizar tais fins, sem conhecer quaisquer limites po parte dos súditos. Os antigos iura quesitae se transformaram em barreiras formais, porque, de fato, não havia nenhuma barreira. ${ }^{42}$ Quanto aos funcionários, seu papel nos negócios públicos era determinado pelo príncipe, a quem estavam submetidos por um severo sistema disciplinar hierárquico. Esta forma de organização do poder público começou a mudar a partir do momento em que a independência dos tribunais foi reconhecida, isto é, em que a justiça civil e a criminal obtiveram uma situação particular diferente da Administração e se tornaram na organização estatal, centro de um poder próprio e independente. ${ }^{43}$ Isso aconteceu a partir da nova noção de lei como ordem geral que se endereça aos súditos e que é publicada, de modo que, quando o prínci pe editava uma re gra de direito civil sob a forma de lei, a mesm restava inviolável, e sua aplicação só dependia de um juiz, que era forçado a aplicá-la. Ao príncipe, não se reconhecia mais sequer o poder de dispensá-la . ${ }^{44}$

37 Cf. GIANNINI, Massimo Severo. Organi(Teoria Generale), in: Enciclopedia del Dinitto, vol.XXXI. Milão: Giuffre, 1981, p. 37.

Cf. MAYER, Otto. Le Droit Administratif Allemand. Paris: V. Giard \& E. Brière, 1903, (traduçâo do próprio autor) pp.. 32 a 42.

Cf. HECK, Luís Afonso. O Tribunal Constitucional Federal e o Desenvolvimento dos Princípios Constitucionais. Contributo para uma compreensāo da Jurisdição Constitucional Alemã. Porto Alegre: Sérgio Antonio Fabris Editor, 1995, p. 24.

to Cf. HECK, (nota 39), p. 44

"Cf. HECK, (nota 39), pp. $44 / 45$

42 Cf. MAYER, (nota 38), p. 44

${ }^{43}$ CF. MAYER, (nota 38) p. 47

C CF. MAYER (nota 38) p. 40 .

Revista da Faculdade de Direito da UFRGS, v. 19, Março/2001
Quanto às leis de polícia, submetiam-se am regime diferente: ao ordenarem casos individuais, vinculavam os funcionários e não o prínci pe e, assim, as 'leis da justiça' obrigavam o governo, e as leis de polícia, não. As leis da justiça eram 'direito', as de polícia, não. O resultado é que, nesse período, existia um direito civil, um direito penal e um direito de procedimento, mas nenhum 'direito público', porque, para a Administração, em relação aos súditos, não havia dever. Quando o direito civil e as jurisdições civis passaram a se ocupar da relação entre o Estado e os súditos, surgiu a questão de submeter o Estado ao direito civil e, do conflito entre duas idéias opostas - idéia do Estado oni potente, que havia derrubado as barreiras dos iura quesitae, e a idéia do direito, isto é, de que as relações entre o Estado e os súditos deviam dar-se sob a forma do direito e suas regras - surgiu a doutrina do Fisco, que acabou por cindir a personalidade jurídica do Estado ${ }^{45}$

Quando o direito público alemão adotou a instituição romana do Fisco, preocupouse, inicialmente, com as vantagens materiais desta instituição: os direitos do fisco, as multas, confiscos, tesouros - o caixa do príncipe - . À medida que o Estado se foi tornando cada vez mais oni potente e os direitos particulares dos príncipes foram desaparecendo, o Fisco, pessoa moral proprietária dos bens destinados à realização dos fins estatais, passou para primeiro plano, distinguindo-se, a partir daí, os bens do Fisco dos bens privados do príncipe. Então, ao lado do Estado propriamente dito (o príncipe e as autoridades que exerciam poderes públicos), foi

reconhecida esta outra pessoa, responsável pela administração dos bens do Estado através de funcionários, que a defendiam perante os tribunais, como parte em um processo. O Estado aparece, assim, como duas pessoas jurídicas distintas, ou seja, ora considerado como uma sociedade de interesses pecuniários ou pessoa moral de direito civil, ora como associação política, pessoa moral de direito público, com direitos de superioridade em relação aos particulares. Segundo a fórmula clássica de Koch, ${ }^{46}$ "O Estado se apresenta como pessoa moral em uma dupla relação, como associação política para a realização do fim do Estado (direitos de majestade, de superioridade) e como sociedade de interesses pecuniários para encontrar os meios que devem servir àquele fim".

Com a doutrina do Fisco, então, foi possivel atribuir efeitos civis imediatamente aos atos do poder público: o Estado desapropria, o Fisco paga a indenização; o Estado nomeia um funcionário, submete-o a uma disciplina especial, o Fisco celebra com ele um contrato de direito civil, para the pagar salários, de modo que, "todas as vezes que o Estado, pela sua potestade pública, impõe a um indivíduo um sacrificio especial, o Fisco, em virtude de uma regra geral de direito civil, se torna seu devedor de uma justa indenização, para cujo pagamento pode ser citado diante de um tribunal civil" ${ }^{47}$ Daí que, não podendo o Estado (no primeiro sentido) restar submetido aos tribunais e ao direito civil, esse realizou, segundo Otto Mayer, "plenamente e sem restrições a idéia que, no regime de polícia triunfou".

${ }^{45}$ Cf. MAYER, (nota 38), p. 55

${ }^{4}$ KOCH. Lehrbuch des Preussischen Privatrechts, I, p. 170, apud Otto MAYER, (nota 38), p. 57.

${ }^{47}$ MAYER, (nota 38), p. 61, verbis: “(...) tout les fois que l'Etat, par sa puissance publique, impose à un individu un sacrifice spécial, le Fisc, en vertu d'une règle générale du droit civil, devient son débiteur d'une juste indemnité, pour le paiement de laquelle on peut l'assigner devant le tribunal civil".

${ }^{48}$ MAYER, (nota 38), p. 58. 
III - A TEORIA DO RECHSSTAAT E A NOVA INTERPRETAÇÃO DA NOÇÃO DE PESSOA JURÍDICA PÚBLICA

A teoria do Rechsstaat formulada pelo teóricos alemães em um regime monárquico, guarda semelhanças com as idéias de Estado Constitucional de tipo francês e com o rule of law britânico, na perspectivação teórico-formal. No Estado Constitucional de tipo francês, a tônica foi colocada nos mecanismos políticos, como controle parlamentar e garantias constitucionais. No princípio do rule of law, exist um só direito no país e uma única ordem de tribunais para aplicá-lo. A Administração está submetida ao Direito (law) tanto quanto os particulares, e o controle é, assim, judicial.Já a teoria alemã do Rechsstaat, ante a impossibilidade de moldar constitucionalmente o Estado em função da garantia dos direitos fundamentais (a burguesia alemã do séc. XIX não conseguiu impor, politicamente, as soluções liberais) perspectiva o Estado de Direito em torno de sua dimensão teórico-formal (princípio da legalidade da Administração e justiça administrativa) e o reduz a 'Estado de legalidade', compatível até mesmo com formas autoritárias de governo.

\section{1 - A perspectivação teórico-formal}

$\mathrm{Na}$ concepção estritamente formal, há coincidência entre Estado e Direito (qualquer Estado é Estado de Direito). ${ }^{50}$ Nesse sentido, $\mathrm{Kelsen}^{51}$ argumenta que todo Estado é de "Di- reito", na medida em que é uma ordem jurídica relativamente centralizada e que, "para ser um Estado, a ordem jurídica necessita ter o caráter de uma organização no sentido estrito da palavra, quer dizer, tem que instituir órgãos funcionando segundo o princípio da divisão do trabalho para a criação e aplicação das normas que o formam".

Schmitt, ${ }^{52}$ da mesma forma, assevera ser o Estado de Direito tão-somente uma "parte" de toda Constituição moderna, cujo conceito se fixou sob o ponto de vista da liberdade burguesa, não significando finalidade e conteúdo do Estado, senão só o caráter de sua realização. Por isso, segundo ele, a expressão é equivocada, já que assim pode ser caracterizado "todo Estado que respeite sem condições ao Direito objetivo vigente e os direitos subjetivos que existam". Daí que o velho Império alemão, ao tempo de sua dissolução, também era um ideal "Estado de Direito" ou uma "união jurídica de domínio"53 - uma materialização da idéia medieval de Direito, que tinha por função assegurar a salvação do Ocidente. O Império era, pois, uma instituição missional, sacralizado por tal finalidade, e uma instituição jurídica cuja função prática mais importante era a administração da justiça por tribunais que eram considerados o refúgio para todos os que se sentissem violados pelas autoridades em seu território. Esses tribunais, sem tomar em consideração privilégios, "admitiam todas as demandas fundadas na denegação de justiça da autoridade territorial". ${ }^{54}$
4 Cf. NOVAIS, Jorge Reis. Contributo para uma Teoria do Estado de Direito. Coimbra, 1987, p. 48 .

» Cf NOVAIS, (nota 49), pp. 12/13.

51 KELSEN, (nota 2), pp.383/390.

S2 SCHMITT, Carl. Teoría de la Constitución. Madrid: Alianza Editorial, 1996, p. 141.

33 HATTENHAUER, Hans. Los Fundamentos Historicos-Ideologicos del Derecho Aleman. Entre la Jerarquia y la Democracia. Madrid: Editoriales de Derecho Reunidas, 1981, p. 31

\section{HATTENHAUER, (nota 53), p. 33.}

Revista da Faculdade de Direito da UFRGS, v. 19, Março/2001
Weber, por igual, a partir da sua ti pologia da dominação $0^{55}$ - que se tornou clássica - destaca que até mesmo a dominação patrimonial ou feudal pode estar reduzida e limitada por determinados meios: privilégios estamentais e, em seu grau máximo, pela divisão estamental de poderes, que conhece exclusivamente sob a forma de concorrência de direitos subjetivos (privilégios ou prerrogativas feudais).$^{56}$ Assim, pode-se falar de um 'estado de direito feudal' ou 'estado de direito estamental' que, frente ao domínio patrimonial 'puro', baseado na coexistência entre a vinculação pela tradição e direitos apropriados com o livre arbítrio e graça do senhor, aproxima-se a uma organização jurídico-pública relativamente constitucional. ${ }^{57}$

Por isso é que Schmitt ${ }^{58}$ afirma ser o Estado de Direito Moderno o 'Estado burguês de Direito', que recebe sua precisa significação quando, para além dos princípios gerais da liberdade burguesa e da defesa do Direito, estabelecem-se critérios orgânicos que passam a ser característicos do 'verdadeiro' Estado de Direito, tais como: a) exigência de 'lei' para interferências na esfera individual (princípio da legalidade da Administração); b) que a atividade total do Estado esteja compreendida, sem resíduo, na soma de competências rigorosamente circunscritas (divisão e distinção dos poderes); c) con-

${ }^{55}$ Segundo WEBER, (nota 18), p. 172, existem três tipos puros de dominação legítima: a) a tradicional, cuja autoridade advém dosmores, do ontem eterno, exercido pelo patriarca e pelo príncipe patrimonial; b) a carismática, assenteno dom da graça exclusivamente pessoal do líder e c) legal, na qual háo domínio em virtude da fé na validade do estatuto legal da competência funcional, baseada em regras racionalmente criadas.

da competência funcional, baseada em

WEBER, (nota 18), p. 821 .

SCHMTTT, (nota 52), pp. 141/147.

s Também para WEBER (nota 18), p. 501, no Estado moderno existe precisamente a tendência de aproximar entre si, do ponto de vista formal, a aplicação do direito e a 'administração' (no sentido de governo), primeiro, entre si, do ponto de vista formal, a a plicação do direito e a 'administração' (no sentido de governo), primeiro,
porque no âmbito da atividade judicial, impóe-se ao juiz a obrigação de resolver as controvérsias atendendo porque no âmbito da atividade judicial, impóe-se ao juiz a obrigação de resolver as controvérsias atendendo
a princípios materiais (moralidade, equidade, conveniência, etc.); em segundo, porque a organização do a princípios materiais (moralidade, equidade, conveniência, etc.); em segundo, porque a organizaçāo do
Estado atual concede ao particular que, em principio, só é objeto da administração, determinados recursos Estado atual concede ao particular que, em principio, só é objeto da administração, determinados recursos
para proteger seus interesses frente à mesma. Tais meios são, ao menos formalmente, idênticos aos de aplicação do direito e, por isso, há, aí, a jurisdição administrativ

C. HATTENHAUER, (nota 53), p. 145

Revista da Faculdade de Direito da UFRGS, v. 19, Março/2001

trole judicial da Administração por juízes independentes que decidam dentro de um procediDesta forma, o ideal pleno do 'Estado burguês de Direito' culmina com uma conformação juem atenção ao caráter político de certas questões litigiosas, esteja previsto um procedimento especial ou uma instância especial (tratamento tra ministros e chefes de Estado, litígios constitucionais autênticos, decisão de dúvidas e divergências de opinião sobre a constitucioespecial bem como tratamento especial dos ato de governo ou atos políticos específicos no ter-

A formulação inicial da teoria do Rechtsstaat ocorreu no âmbito da 'revolução burguesa' alemã de 1848, em que o "cidadão se cipação de seu 'direito civil'. A realização desta exigencia se traduziu, primeiramente, na Consjurídico unitário prevendo a promulgação de Codigos Gerais de direito civil, direito mercant direito penal e procedimento jud 
pério, foi criado um tribunal próprio, entendido como organização da cidadania e como "uma instituição para garantir a liberdade civil." A proteção jurídica da liberdade deveria ser afinal, 'proteção constitucional' e, da mesma forma, a Constituição deveria ser garantida por um juiz. Daí ter sido proclamada a cessação da atividade administrativa contenciosa pelos órgãos da Administração direta e prevista a competência dos tribunais ordinários para todas as controvérsias, fossem elas de direito privado e ou de direito público.$^{62} \mathrm{O}$ que se protegia eram as posições do indivíduo contra o Estado - status negativo - agora sob nome de 'catálogo de direitos fundamentais", isto é, especificação jurídica dos postulados filosóficos do Iluminismo. ${ }^{63}$ $\mathrm{Na}$ Prússia, a partir da Constituição de 1850 consolida-se outro postulado liberal, o da independência judicial, de modo que os juízes servissem de mediadores entre forças oponentes e estivessem obrigados apenas por lei. ${ }^{64}$

Nesse contexto, um juiz do Estado de Hesse, Wilhelm Pfeiffer, em 1851, publica um tratado intitulado 'A autonomia e independência da judicatura. Uma séria advertência', arrolando uma série de requisitos que podiam assegurar a independência judicial, dentre os quais o da necessária "separação entre assuntos judiciais, por uma parte, e assuntos de Governo e Administração, por outra" ${ }^{65}$ e o da probição de "transferência de funçōes juđiciais às autoridades administrativas". Em 1864, Otto Bähr pu-

blica um estudo denominado "Rechtsstaat"(termo que procedia de Mohl e que já havia sido utilizado por Sthal), em que, tratando do problema de como deve realizar-se a tutela jurídica do cidadão no âmbito do Direito Público, ${ }^{66}$ afirma a necessidade de separar-se a Justiça da Administração e de reconhecer-se, no âmbito do Direito Público, "uma jurisdição autônoma e independente como imperativo de justiça". ${ }^{67}$ A partir daí, em vários Estados alemães foram criadas instâncias jurisdicionais administrativas, segundo duas diferentes orientações doutrináras: a primeira, defendida por Otto Bähr, de cunho mais subjetivístico, pela qual a tutela jurisdicional só poderia ser invocada na presença de direitos subjetivos, isto é, a atividade jurisdicional era tão-somente a tutela da esfera jurídica individual, ${ }^{68}$ a segunda orientação, de fendida por Rudolf von Gneist, configurava a justiça administrativa como controle objetivo da atividade administrativa, de modo "a eliminar o exercício parcial e iníquo do poder administrativo" ${ }^{\prime 6}$ e de forma que a jurisdição administrativa fosse a colaboração contenciosa do cidadão com a Administração. Esta orientação objetivística foi a que prevaleceu de forma geral na Alemanha (com exceção dos Estados do sul), após 1871, respondendo ao problema da proteção do indivíduo frente à Administração e à idéia, presente na cultura germânica, contrária à sobreposição da Administração - núcleo fundamental do Estado - aos tribunais ordinários. A orientação objetivística também traduzia ade-

${ }^{62}$ Cf. MASUCCI, Alfonso. La legge tedesca sul processo admministrativo. $\underline{\text { In}}$ : Quaderni di Diritto processuale amministrativo. Milão: Giuffrè, 1991,p. 4

${ }^{63}$ Cf. HATTENHAUER, (nota 53), p. 147

of Cf. HATTENHAUER, (nota 53), p. 151

as HATTENHAUER, (nota 53), p. 157.

${ }^{\circ}$ Cf. HATTENHAUER, (nota 53), pp. 158/159.

67 HATTENHAUER, (nota 53), p. 159

${ }^{68}$ Segundo MASUCCI, (nota 62), p. 4, só em tal caso havia ação (Klage). Do contrário, ante um interesse, a via era um recurso (Beschwerde) aos órgãos da Administração ativa.

@MASUCCI, (nota 62), p. 5 .

Revista da Faculdade de Direito da UFRGS, v. 19, Março/200 quadamente a concepção político-jurídica que considerava ser finalidade do Estado a defesa do ordenamento jurídico, sendo este último um meio de organização dos interesses coletivos do cidadãos. Onde prevaleceu a concepção subjetivística da tutela jurisdicional administrativa, a competência do juiz estava limitada à verificação da legitimidade formal do procedimento; nos Estados em que prevaleceu a concepção objetivística, ao contrário, a competência dos juízes não só verificava a legitimidade, mas também o mérito administrativo. A evolução da jurisdição administrativa tedesca iria oscilar entre esses dois polos, até sua defintiva consagração pela Lei Fundamental de Bonn e a unificação do processo administrativo, ocorrida em 21 de janeiro de $19600^{70}$

Assim, a expressão Rechsstaat fez fortuna no âmbito da ciência política para designa um tipo de Estado qualificado por seus fin morais, contraposto ao Estado patriarcal, despótico, etc. ${ }^{71}$ Estado de Direito é aquele que visa a realização e a manutenção do direito da ordem legal. Já a noção jurídica de Estado de Direito, consolidada no II Império Alemão (1871), está ligada não a teorias filosóficas, mas a uma teoria jurídica que "se refere exclusivamente ao método segundo o qual procedem os órgãos do Estado"72 e, por isso, na base da conversão do problema de limitação do poder político em problema jurídico está a teoria da personalização jurídica do Estado, uma vez que o converteu em sujeito de direito, capaz de estabelecer relações com os demais sujeitos - os súditos -, fazendo com que tais relações pudes-

em ser efetivamente disci plinadas pelo Direito.

A doutrina do Estado de Direito, ao significar a conversão do antigo problema de limitação do poder político em problema jurídico, não o reduziu, no entanto, a uma simples vinculação à lei editada pelo Poder soberano o Legislativo - . Através do Estado de Direito, reivindica-se um direito igual para todos, válido universalmente, pois é a regulamentação abstrata, geral e anterior que garante a igualdade perante a lei (outro princípio fundamental do $\mathrm{Di}$ reito Público, que, aliás, como um conjunto de regras jurídicas distintas das de Direito Privado, consolida-se nessa época), bem como a vinculação das autoridades políticas e dos cidadãos pelas leis e atos que lhe são assimiláveis. Reivindica-se, igualmente, que a autoridade observe o Princípio da Legalidade, no exercício de seu poder discricionário. ${ }^{73}$

3.2 - Os poderes estatais como órgãos que exercem funções públicas

Reagindo contra o Estado de Polícia, então, a ciência jurídica oitocentista, principalmente a alemã, tratou de incorporar o valor político fundamental da burguesia ascendente, qual seja, o de controlar o exercício do poder do governo e salvaguardar os direitos fundamentais, configurando o Estado como entidade jurídica unitária cuja situação jurídica - poderes, direitos, obrigações - estivessse rigidamente determinada por normas ditadas pelo Parlamento - órgão da representação do povo. ${ }^{74} \mathrm{Na}$

70 Cr. MASUCCI (nota 62), pp. 10/11 e FROMONT, Michel. La répartition des compétences entre les Cf. MASUCCI (nota 62), pp. 10/11 e FROMONT, Michel. La répartition
tribunaux civils et adminstratifs en droit allemand. Paris: LGDJ, 1960, p.13.

(1) Cf STASSINOPOULOS, Michel.Traité des Actes Administratifs. Atenas: Collection de L'Institut Français d'Athènes, 1954, p. 18.

37 STASSINOPOULOS, (nota 71), p. 18

Cf. FLEINER, Fritz. Les Princi pes Généraux du Droit Administratif Allemand. Paris: Delagrave, 1933, pp. 92,93 e ENTERRIA, Eduardo Garcia. Revolucion Francesa y Administracion Contemporanea. $4^{\underline{z}}$ ed. Madrid: Civitas, 1994, pp. 37/39.

it GLANINNI, (nota 37), p. 39. 

leitura se apresentava como um sujeito que não figura da 'pessoa jurídica', objeto de uma ininterrupta reelaboração, os publicistas puderam encontrar um instrumento para essa reação, e a 'pessoa moral' do Estado apareceu armada de uma vontade juridicamente superior à vontade de todas as demais pessoas, fisicas ou jurídicas. Laband,$^{75}$ tentando resolver o problema da natureza jurídica do novo Império, postula que os soberanos são "órgãos do povo" e que o Estado é mais do que a soma de todos os cidadãos: é uma pessoa jurídica real com capacidade jurídica própria que se manifesta no poder soberano. Como anota Hattenhauer "nesta definição do novo Império não figurava nem o Parlamento nem o cidadão em particular como titular de um poder jurídico relevante" ${ }^{76}$

Porque a 'pessoa jurídica' em sua última tinha capacidade de agir por si mesmo (essa capacidade era reconduzida aos seus legais representantes), os publicistas, ao advogarem a tese da personificação do Estado, viram-se diante dos seguintes problemas: se o chefe do Estado era seu 'representante' nas relações internacionais, mas não nas relações internas; se os ministros, prefeitos, procuradores da fazenda podiam adotar procedimentos administrativos e concluir contratos; se os juízes e parlamentares eram 're-

presentantes' do Estado, a tutela das partes, do cidadão, ante atos ilegítimos dos representante do Estado não ficava diminuída? No fim das contas, o Estado e seus funcionários não restariam irresponsáveis? De modo a responder esta questões e ainda as relativas à pluralidade d representantes, aos possíveis conflitos entre os mesmos, à diminuição da tutela dos cidadãos ante a clara impossibilidade de configurar como representantes serviços não internos, modificouse o tipo de imputação, eliminando intermediação do representante e configurando o serviço mesmo como ente, instrumento de imputação imediata e direta do Estado, isto é, como órgão. É por isso que o conceito de órgão se tornou o elemento estrutural da teoria da pessoa jurídica, ${ }^{77}$ pois órgãos 'presentam' pessoas, isto é, atuam por elas, ${ }^{78}$ e a ' pessoa jurídica' nada mais é do que uma relação de direito ou "um vínculo jurídico". ${ }^{79}$ Afirma Giannini, que o conceito de órgão foi, por isso mesmo, uma "conquista civil", 80 pois tornou possível aperfeiçoar a tutela da liberdade e dos direitos do cidadão no confronto com o poder público e localizar apropriadamente as várias instâncias existentes em um corpo social, dando presença jurídica definida aos interesses públicos e coletivos heterogêneos.

${ }^{75}$ Cf. HATTENHAUER, (nota 53), p. 246

${ }^{76}$ HATTENHAUER, (nota 53), p. 248

"PONTES DE MIRANDA, Francisco Cavalcanti. Tratado de Direito Privado. Tomo I. Rio de Janeiro: Editora Borsoi, 1954, $2^{a}$ ed., p. 282, assevera que a pessoa, sendo uma criação do direito, imputa-se capacidade de obrar. No caso das pessoas juridicas, é o órgăo, ou orgãos (em caso de distribuição de funçóes) que praticam seus atos, "porque os órgãos são parte dela, como o braço, a bôca, o ouvido, são órgãos da pessoa fisica". Assim, "o orgão não representa; presenta, pois é órgão"(pág. 286), e inexiste pessoa jurídica sem é capaz de obrar"(p. 287).

${ }^{78}$ Cf. PONTES DE MIRANDA, (nota 77), pp. 280.

${ }_{79}$ CIRNE LIMA, Ruy. Princípios de Direito Administrativo. 6a. Ed. São Paulo: RT, 1987, pp. 63/64: "A pessoa jurídica é uma relação de direito, estabelecida entre duas ou mais pessoas, para a unificação e, não raro, para a perpetuação em unidade, quanto a bens comuns e atos determinados, das virtualidades juŕdicas ina na capacidade de agir de cada uma. (. A essa relacão de direito, a êsse vínculo jú́dico, dése a denom, insitas so GIANINNI, (nota 37), pág. 41.

Revista da Faculdade de Direito da UFRGS, v. 19, Març/2001 órgão, "inclusive sem órgão para a vida externa. Exatamente porque o órgão não representa, a pessoa jurídica na capacidade de agì de cada uma.....) A essa relaçáo de direilo, a esse vinculo juridico, dâ-se a denominaçẫo
O conceito de órgão, então, fruto do constitucionalismo do séc. XIX e do organicismo alemão, passa a ser a idéia de "multiplicação de centros de poder e manifestação, no interio do Estado, de diferentes interesses e posiçõe políticas" 81 ou o princípio vital de integração de vontades e de manifestação do fenômeno estatal. A tese da personalidade jurídica do Estado que lhe é conexa, serviu à institucionalização e cen tralização do poder, ao substituir a vontade do mo narca pela do Estado, de modo que este pudesse submeter-se ao Direito e favorecer a centralização e hierarquização da organização administrativa, concebida à maneira de um "homem em ponto grande".

Consagrada a tese da personificação do Estado, considera-se este pessoa jurídica de direito público (política), em contraposição à pessoas jurídicas de direito privado, identificamse seus poderes com os órgãos que exercem as funções estatais (Poder Legislativo, Poder Executivo, Poder Judiciário), e o conceito ganh interesse, conforme Jorge Miranda ${ }^{82}$ sobretudo porque, além de propiciar "um instrumento de mediação entre a colectividade e a vontade ou poder que a unifica", explica o fenômeno da transformação da vontade individual em vontade funcional, ${ }^{83}$ indica que o poder político perplano da dogmática jurídica, o fenômeno da divisão do poder político, através de diversos órgãos com competência própria" e, finalmente, permite resolver problemas de responsabilidade.

Ademais, quando o Estado passa a ser uma 'pessoa jurídica' e, por isso, sujeito de relações jurídcas (como credor ou devedor), torna-se responsável juridicamente por suas ações ou omissões e, ao mesmo tempo, titular de direitos frente aos administrados. A alteração básica - relativamente à anterior teoria do Fisco - está no regime jurídico que rege tais relações: antes, direito privado, agora, um especifico regime de direito público. Daí ser a nota característica do Estado Moderno o reconhecimento dos súditos como sujeitos de direito capazes de reclamar uma tutela efetiva. SegundoJellineck, "as pretensões jurídicas que direitos subjectivos públicos'\$4 ${ }^{\text {'84 }}$, sob esta expressão, compreendem-se quatro relações possiviveis entre 0 Estado e os administrados: status subjectionis (status passivo, de subordinação ou ausência de personalidade); status libertatis(statusnegativo, em que o indivíduo é titular de uma margem de liberdade individual, a margem da intervenção estatal); status civitatis (status positivo, em que o indivíduo tem direito à prestações) e status activae civitatis (situação em que o indivíduo é sujeito do poder político, tendo o direto de participar do poder). manece íntegro apesar da mudança dos indiví-

duos nele investidos, "ajuda a compreender, no resultam de tais condições são o que se designa por

${ }^{81}$ Cf. MIRANDA, Jorge. Funçōes, Órgãos e Actos do Estado. (Apontamento de lições). Lisboa: Faculdade de Direito da Universidade de Lisboa, 1990, p. 40.

${ }^{82}$ KELSEN, (nota 2) p. 42/43.

${ }^{83}$ MIRANDA, (nota 81), p. 47, defende que a noção de órgão, atualmente, explica justamente este fenômeno de "transformação da vontade psicologica (de certas pessoas fisicas - os governantes e outros detentores do poder político) em vontade funcio al (em vo certe do Estado ou da pessoa colectiva)", istó é a imputacão. poder politico) em vontade funcional (em von "No Estado (como, em geral, nas pessoas colectivs, verato, a definição normativa de centros de formação da vontade colectiva $e$, por outos discas da função de os preencherem em concreto, de agirem como se fossem o Estado a agir. E então, a vontade que estas pessoas singulares formem - uma vontade psicologica, como qual quer outra - e tda como vontade da pessoa colectiva e qualquer acto que pratiquem, automatcanente enquanto tal, a ele atribuido. Nisto consiste o fenonemo da
imputacão". imputação"

JELLINECK. System des subjektiven öffentliche Rechte, 1892,p. 96, apud NOVAIS (nota 49), p. 79. Para Jellineck, os direitos subjetivos constituem pretensões jurídicas (Ansprüchen) que resultam diretamente de condiçôes jurídicas (Zustände). 
Consagrou-se, enfim, no direito moderno a idéia de que a competência própria de cada órgão é uma determinação de suas tare fas, que cria a obrigação para o órgão de ag unicamente nos limites de suas funções. Dado que o primeiro elemento fundamental da noção jurídica de 'Estado de Direito' é a separação de poderes ou a separação orgânica da funções, como formulado por Montesquieu, cada função restou confiada a um órgão particular. Sendo três as funções, três grupos distintos de órgãos são formados: órgãos legislativos, órgão administrativos e órgãos jurisdicionais, e da re partição de tarefas entre esses três grupos de órgãos, decorre a noção de "competência funcional' ou 'competência de direção'. ${ }^{85}$

A partir daí, delineou-se um "conceito jurídico-organizatório do Estado" 86 que, hoje, deixou de ser adequado porque não explica as relações interorgânicas dos vários órgãos constitucionais e não oferece soluções satisfatórias para os conflitos orgâncos. Tais relações e litígios põem em causa a idéia $\mathrm{d}$ unidade da pessoa jurídica do Estado e a sua operacionalidade como centro de imputações de todos os atos referentes aos órgãos estatais. Por isso, 0 conceito jurídico-constitucional de Estado, na atualdade, perspectiva-se como "ordenação de várias funções constitucionalmente atribuídas a vários órgãos constitucionais", ${ }^{87}$ de modo a aparecer 'repartida' ou 'separada' a atividade do Estado e não o seu poder a resultante dessa divisão passa a ser uma diferenciação de funções e não a existência de vários poderes.

A Administração Pública, entretanto, per-

manece sendo descrita como uma 'pessoa' porque adquiriu uma estrutura unificada e hierarquizada, em que a competência dos diversos órgãos se encontra escalonada e encadeada à semelhança de uma pirâmide em cujo ápice se encontra, geralmente, o Chefe do Executivo, conforme esteja definido na Constituição. No Brasil, por exemplo, a Presidência da República é o órgão supremo da Administração, e a Lei $9.874 / 99,{ }^{88}$ além de referir serem seus preceitos aplicáveis "aos órgãos dos Poderes Legislativo e Judiciário da União quando no desempenho de função administrativa" ( $\S 1^{\circ}$, art. $1^{\circ}$ ), define como 'órgão' "a unidade de atuação integrante da Administração direta e da estrutura da Administração indireta" (art. 1ํ, § 2oo, I).

No plano do direito administrativo, há sempre que se considerar também a distinção, deveras essencial, entre pessoa jurídica de direito público e pessoa jurídica de direito privado, pois, de um lado, tem-se as pessoas jurídicas de natureza política e existência necessária, que nascem com a Constituição, e em contrapartida as "de natureza puramente administrativa e existência contingente", ${ }^{89}$ que são as criadas por lei ordinária com vistas à realização de determinados fins estatais, como o provimento de determinada necessidade pública diferenciada.

Em síntese, foi a publicização da noção de pessoa jurídica, efetuada através da teoria orgânica que tornou possivel a construção dogmática do Estado de Direito, pois este é a organização política em que estão assegurados os direitos fundamentais e a separação de poderes, que nada mais é do que a rigorosa circunscrição de competências funcionais.

${ }^{85}$ STASSINOPOULOS, (nota 71), p. 18

${ }_{86}$ CANOTILHO, José Joaquim Gomes. Direito Constitucional. Coimbra: Almedina, 1993, p. 682

${ }^{87}$ CANOTILHO, José Joaquim Go

${ }^{87}$ CANOTLHO, (nota 86), p. 682. BRASIL. Lei 9.784, de 29 de janeiro de 1999. Regula o processo administrativo no âmbito da Administração
Pública Federal. Informação por correio eletrônico. http://www.mare.gov.br/Legis/_Docs/Leis/9784_99.htm.

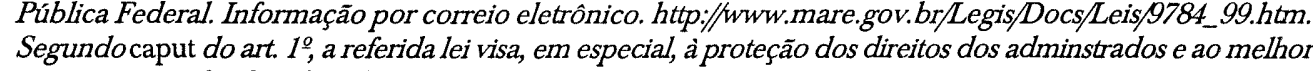
cumprimento dos fins da Administração.

a9 Cf. CIRNE LIMA (nota 79), p. 63

Revista da Faculdade de Direito da UFRGS, v. 19, Marco/2001

\title{
A Redução Voluntária de Capital
} Social nas Sociedades Anônimas

\author{
Maria Monorina de Bittencourt Souza \\ Advogada e Assessora Técnica do Registro do Comércio
}

$$
\begin{gathered}
\text { Michel Zavagna Gralha } \\
\text { Acadêmico de Direito }
\end{gathered}
$$

Is cidas como sociedades anônimas ou companhia, de natureza obrigatoriamente comercial, têm peculiaridades inconfundíveis desde sua origem.

A característica princi pal das sociedades anônimas é o papel relevante que se atribui ao seu capital social, aí compreendido sua formação, integridade e modificações. O tratamento cuidadoso que a legislação impõe decorre exatamente de ser este tipo jurídico, uma sociedade de capital, cujas relações de mercado vão depender de sua representatividade, garantia e integridade.

Sendo assim, as modificações do seu capital social deverão atender aos limites impostos pela legislação cuidando que se evite risco, não apenas ao próprio ente, como também a seus acionistas e investidores. $\mathrm{O}$ aumento ou redução do capital social deve observar as disposições legais e estatutárias. A redução, por suas conseqüências, mereceu maiores cuidados do legislador e pode ocorrer através do resgate, do reembolso, da cisão parcial, da inadimplência do acionista, da absorção dos prejuízos acumu- lados ou ainda, quando o capital for considerado excessivo.

A redução do capital para absorver prejuízos ou porque foi julgado excessivo, tal como previsto nos arts. 173 e 174 da Lei n. .6 .404 , de 15 de dezembro de $1976^{1}$, é considerada uma redução voluntária, tendo tratamento diferenciado dos demais casos.

\section{Conforme dispõe o art. 173:}

"A Assembléia Geral poderá deliberar a redução do capital social se houver perda, até o montante dos prejuízos acumulados, ou se julgá-los excessivo.

$\$ 1^{\circ}$ A proposta de redução do capital social, quando de iniciativa dos administradores, não poderá ser submetida à deliberação da Assembléia Geral sem o parecer do conselho fiscal, se em funcionamento.

$\$ 2^{\circ}$ A partir da deliberação de redução ficarão suspensos os direitos correspondentes às açôes cujos certificados tenham sido emitidos, até que sejam apresentados à companhia para substituição."

'Publicada no Diário Oficial da União de 17 de dezembro de 1976. Suplemento, p.1. 